\title{
INTENSIVE CARE
}

\section{Dysoxia and lactate}

Trevor Duke

Disturbances of oxygen supply or cellular oxygen metabolism are common in critically ill patients. An understanding of dysoxia, or oxygen limited energy depletion, requires an understanding of the normal physiology of cell oxygen metabolism, and the compensatory mechanisms that supply high energy molecules under conditions of hypoxia. Understanding disorders associated with hyperlactataemia requires consideration of the cellular response in dysoxia, and pathology specific derangements in lactate metabolism. Much has recently been discovered about the causes of lactic acidosis in sepsis, and about the role of lactate in monitoring critically ill children.

This review discusses how cells produce energy for metabolism under normal and hypoxic conditions; what happens to lactate produced during these processes; the clinical situations in which lactic acidosis has been described; the reasons why excess lactate may occur in sepsis; the evidence that a high lactate concentration is not simply a surrogate for tissue dysoxia; the relevance of lactate in the management of critically ill children; and suggested strategies to manage high blood lactate.

\section{Normal cellular oxygen metabolism}

Cells require oxygen for the production of ATP, the principal energy source. ATP is hydrolysed to ADP and high energy phosphate by adenosine triphosphatases in the cytosol. ${ }^{1}$ Energy released is used for the maintenance of membrane integrity, ionic pumps, and other specialised functions, such as contractility of muscle cells, and impulse transmission in neurons. The body's stores of ATP will last no more than a few minutes, so it must be synthesised continuously as it is being used. Under physiological conditions, most ATP is generated from the metabolism of glucose, by the process of oxidative phosphorylation. The first stage of oxidative phosphorylation is the conversion of glucose to pyruvic acid; this occurs in the cytoplasm. The second stage, the oxidation of pyruvic acid, can only occur in the mitochondria as part of the Krebs (citric acid) cycle. Oxidative phosphorylation produces a net 36 molecules of ATP (or $1270 \mathrm{~kJ}$ of available energy) for every glucose molecule oxidised.

Under normal conditions some tissues, such Dr Duke.

e-mail: duke@global.net.pg rather than glucose, as the substrate for ATP generation. In myocytes, palmitate forms about $60 \%$ of the total substrate metabolised, glucose $10 \%$, and lactate $30 \%$. During cellular hypoxia the consumption of lactate ceases, and that of glucose increases to $90 \%$ of the total substrate consumed. $^{2}$ The brain, on the other hand, under any conditions can use only glucose or ketone bodies for ATP production.

\section{Thresholds of hypoxia and cell (dys)function}

Oxidative phosphorylation can only occur when the partial pressure of oxygen $\left(\mathrm{PO}_{2}\right)$ within the mitochondrion is above a critical level, thought to be in the order of $1 \mathrm{~mm} \mathrm{Hg}$ $(0.13 \mathrm{kPa}) .^{3}$ Although the $\mathrm{PO}_{2}$ of dry air at sea level is $159 \mathrm{~mm} \mathrm{Hg}$, and the alveolar $\mathrm{PO}_{2}$ is about $100 \mathrm{~mm} \mathrm{Hg}$, the mean capillary blood $\mathrm{PO}_{2}$ is $50 \mathrm{~mm} \mathrm{Hg}$. From the capillaries oxygen diffuses down a further concentration gradient from one cell to another, and within cells, such that normal mitochondrial $\mathrm{PO}_{2}$ is in the order of $4-20 \mathrm{~mm} \mathrm{Hg}(0.5-2.7 \mathrm{kPa})$. $^{3}$ Some cells, such as the centrilobular cells in the liver, are particularly susceptible to hypoxia because they are further away from capillaries. These undergo necrosis early under hypoxic conditions.

Connett et al defined three theoretical thresholds of cell hypoxia. ${ }^{4}$ The first threshold is crossed when cell oxygen decreases but ATP production is maintained at a level sufficient to match ATP demand by metabolic adaptation. Adaptation involves recruitment of the redox component of electron transport, changes in the phosphorylation states of mitochondria, and increased glycolysis. The critical level of mitochondrial $\mathrm{PO}_{2}$ for oxidative phosphorylation depends on the cells ability to adapt the phosphorylation process metabolically, and the level of ATP demand.

The second threshold occurs when steady state ATP turnover can only be maintained by supplementary production of ATP from anaerobic glycolysis, by the Embden-Meyerhof pathway. This energy inefficient mechanism for producing high energy molecules generates only two molecules of ATP ( $67 \mathrm{~kJ}$ of available energy) for every molecule of glucose metabolised. The pathway must therefore either consume relatively larger quantities of glucose or, alternatively, yield much less ATP. In high energy consuming organs, such as the brain, 
kidney, and liver, the rapid transfer of such quantities of glucose across cell membranes is not possible. Therefore, these organs develop ATP depletion rapidly under hypoxic conditions. Dysoxia can be defined below the second threshold, where ATP production becomes oxygen limited. The third threshold is crossed when glycolysis becomes insufficient to produce enough ATP to maintain cell function and structural integrity.

Most data on cell dysfunction in hypoxia are from in vitro studies; mechanisms are complex and poorly understood, and application to clinical pathophysiology is speculative. Technology, such as nuclear magnetic resonance spectroscopy, which will non-invasively measure cell biochemical changes, is as yet impractical in acute clinical settings.

The effects of ATP depletion on cell function can be divided into those occurring as a result of the initial hypoxic insult, and those that result from reperfusion or reoxygenation. Depletion of ATP results in loss of function of sodium/potassium $\left(\mathrm{Na}^{+} / \mathrm{K}^{+}\right)^{5}$ channels, leading to accumulation of intracellular $\mathrm{Na}^{+}$. Because cell membrane synthesis is a continuous energy requiring process, ATP depletion leads to loss of cell membrane integrity. This, and the accumulation of intracellular $\mathrm{Na}^{+}$, results in cell swelling. Similarly, there is disruption of lysosomal membranes and release of enzymes into the cytosol, causing autolysis. Massive influx of $\mathrm{Na}^{+}$inhibits or reverses the sodium/ calcium $\left(\mathrm{Na}^{+} / \mathrm{Ca}^{2+}\right)$ ion channel, and is one mechanism leading to the intracellular sequestration of $\mathrm{Ca}^{2+}$. Intracellular $\mathrm{Ca}^{2+}$ increases during the first 30 minutes of hypoxia, but can decrease to normal when hypoxia is of longer duration. However, during reperfusion there is

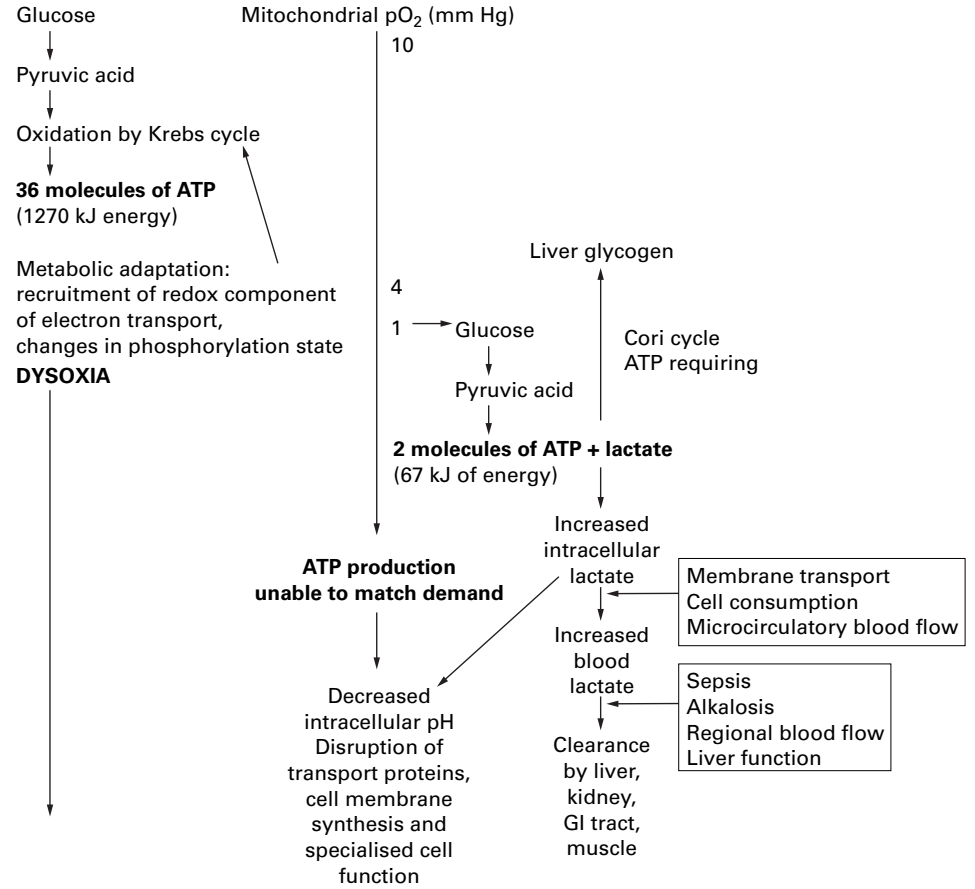

Figure 1 The effect of decreasing mitochondrial partial pressure of $\mathrm{O}_{2}\left(\mathrm{PO}_{2}\right)$ on cellular ATP production, and mechanisms of lactate production and elimination. Factors influencing lactate clearance are in boxes. Critical levels of mitochondrial $\mathrm{PO}_{2}$ for dysoxia depend upon ATP demand. GI, gastrointestinal. a pronounced increase in cytosol $\mathrm{Ca}^{2+} \cdot{ }^{6-8} \mathrm{Ca}^{2+}$ activated proteases can destroy the sarcolemma and the cytoskeleton; $\mathrm{Ca}^{2+}$ activated phospholipases further degrade membrane phospholipids. Concurrent with the depletion of intracellular ATP there is an accumulation of AMP. AMP is released from the cell into the interstitium, where it is dephosphorylated rapidly to adenosine. Adenosine acts as a vasodilator in most vascular beds, improving blood flow in capillaries, but acts as a vasoconstrictor in the renal vascular bed. During reoxygenation, adenosine is a source of oxygen radicals through the formation of inosine, hypoxanthine, and xanthine. Oxygen radicals cause cell damage by lipid peroxidation, release of excitatory amino acids, and inhibition of enzymes.

\section{Lactate production and elimination}

Anaerobic metabolism is not only energy inefficient and unsustainable, but it produces two molecules of lactic acid for every molecule of glucose metabolised. Although lactic acid has energy potential, it is only in the presence of oxygen that it can be reconverted into pyruvic acid, which in turn can be metabolised in the citric acid cycle. Lactic acid can be converted into glucose, by the process of gluconeogenesis (Cori cycle, requiring six molecules of ATP), and stored in the liver as glycogen. This is also an ATP requiring process.

Under normal conditions, the liver has a large capacity for lactate removal, and other organs including the kidneys, gastrointestinal tract, and muscle also remove lactate. Lactate production has to be substantially increased before the metabolic threshold of the liver and other organs is exceeded, and increased blood concentrations occur. Lactate accumulation depends on the rate of glycolysis, the exchange of lactate across cell membranes, washout by the circulation, and consumption and clearance by tissues. ${ }^{4}$ Lactate clearance by the liver and other organs may be reduced in sepsis ${ }^{9}$ and in respiratory alkalosis. ${ }^{10}$

Other conditions interfere with lactate production, so that despite tissue hypoxia, blood lactate will be normal. In severe malnutritionfor example, glucose stores are insufficient to sustain glycolysis. Figure 1 outlines the mechanisms of lactate production and elimination.

Most plasma cell membranes contain a symport for lactate and hydrogen ions, and lactic acid produced in cells is released into the circulation. In the brain, however, excess lactate accumulates in neurons, because the blood-brain barrier is relatively impermeable to charged ions. In severe cerebral hypoxia, some of the brain tissue injury might be caused by intracellular acidosis, in addition to the depletion of high energy compounds.

\section{The clinical relevance of high blood} lactate

High lactate concentrations are seen in the setting of circulatory shock as a result of haemorrhage, myocardial failure, burns, and sepsis ${ }^{11-16}$; after cardiopulmonary bypass ${ }^{17-19}$; and after liver transplantation. ${ }^{20}$ Lactic acidosis might exist not only in the presence of hypotension 
and low cardiac output, but also in normotensive patients with a normal or high cardiac output. ${ }^{21} 22$ Situations where the rate of glycolysis exceeds the rate of pyruvate utilisation by the Krebs cycle include alkalosis, and excess catecholamine release, and are also associated with hyperlactataemia. ${ }^{23}$ Drugs and chemicals that interfere with gluconeogenesis, such as ethanol, methanol, ethylene glycol, salicylates, and phenformin, can also raise lactate concentrations. ${ }^{23}$ Congenital defects of mitochondrial function also present with hyperlactataemia.

The association of lactic acidosis with increased mortality in critically ill patients is well recognised. ${ }^{1624-26}$ In a heterogeneous group of 126 severely ill adults with metabolic acidosis, defined as a lactate $\geqslant 5 \mathrm{mmol} / \mathrm{l}$, and either an arterial $\mathrm{pH} \leqslant 7.35$ or a base deficit $>6 \mathrm{mmol} / \mathrm{l}$, Stacpoole and colleagues ${ }^{11}$ found higher lactate concentrations in non-survivors (mean, 12.2; SD, $5.9 \mathrm{mmol} / \mathrm{l}$ ) than survivors (mean, 9.2; SD, $4.9 \mathrm{mmol} / \mathrm{l} ; \mathrm{p}=0.004$ ). Less than $17 \%$ of the patients in this series survived to hospital discharge. ${ }^{13}$

Mild hyperlactataemia with respiratory alkalosis might not have the same adverse prognostic value as hyperlactataemia with acidosis. Some authors have proposed that mild rises in lactate are not indicative of serious pathology, depending on the mechanism involved. ${ }^{9} 1026$

In critically ill patients, there is some value in the trend of change in lactate as a means of assessing response to treatment, and prognosis. ${ }^{15} 1827-29$ Vincent et al described the time course of blood lactate in adults who responded to rapid volume resuscitation for circulatory shock. ${ }^{15}$ In all cases, during the first hour there was at least a $10 \%$ reduction in blood lactate. This contrasted with patients who died during circulatory shock, in whom lactate concentrations did not change with resuscitation. In a study of adults with sepsis, Tuchschmidt and colleagues ${ }^{30}$ observed that despite the similarity in oxygen consumption $\left(\mathrm{VO}_{2}\right)$ after the initial resuscitation period among survivors and non-survivors, lactate concentrations decreased in the survivors, but not in those who died.

\section{Cause of hyperlactataemia in sepsis}

The traditional distinction between type A (where there is clinical evidence of tissue hypoxia) and type $\mathrm{B}$ lactic acidosis (where there is no clinical evidence of tissue hypoxia) proposed by Cohen and Woods ${ }^{31}$ is simplistic in sepsis. Several mechanisms are involved. Clinical application of this distinction also implies that there is a valid gold standard for the measurement of tissue hypoxia, which is arguable.

Tissue hypoxia can occur because of a decrease in oxygen delivery in hypodynamic sepsis. Sepsis with low cardiac output and peripheral vasoconstriction might be more common in young children, and is a well described feature of severe meningococcal sepsis. ${ }^{32}{ }^{33}$ Even a normal or raised cardiac output might not supply sufficient oxygen to tissues that have an increased metabolic rate.
Hypoxia induced hyperlactataemia might also occur because of the formation of peripheral arterio-venous shunts, or the regional redistribution of blood away from the hepatosplanchnic vascular bed. The true role of impaired cellular oxygen delivery $\left(\mathrm{DO}_{2}\right)$ in sepsis is uncertain, however, because covert tissue hypoxia might not be a common antecedent for lactic acidosis or adverse sequelae in sepsis. ${ }^{34}$

Although there is some evidence for a relation between delivery dependent oxygen consumption and lactate, this has not been shown in all studies, and cannot be generalised to all septic patients. In support of lactate reflecting delivery dependent oxygen consumption, Gilbert and collegues ${ }^{35}$ showed that patients with a high lactate had significant increases in $\mathrm{VO}_{2}$ in response to colloid fluid volume expansion and packed red cell transfusion, whereas patients with normal lactate had no such increase in $\mathrm{VO}_{2}$. Against these findings are those of Silverman, ${ }^{14}$ who used intravenous fluids, packed red cell transfusion, and dobutamine infusion to improve $\mathrm{DO}_{2}$ in 17 adults with sepsis. Of 52 interventions that improved $\mathrm{DO}_{2}$ and $\mathrm{VO}_{2}$ in the 17 patients, about one third were associated with an unchanged, or increased, blood lactate. There was no predictable relation between improvements in $\mathrm{VO}_{2}$ and reductions in blood lactate.

Further evidence has been used to argue against tissue hypoxia as the major cause of lactic acidosis, namely: (1) the effect of sodium dichloroacetate (DCA) on lactate concentrations in sepsis ${ }^{36}$; (2) the finding that in patients with mild rises of blood lactate, clearance is reduced rather than lactate production increased $^{9}$; (3) in clinical studies, efforts to drive $\mathrm{DO}_{2}$ to supranormal levels do not consistently improve outcome $\mathrm{e}^{37}$ or lower blood lactate $^{38} ;(4)$ in some models of sepsis, organ failure occurs despite levels of $\mathrm{VO}_{2}$ and $\mathrm{DO}_{2}$ within the physiological range ${ }^{39}$; and (5) in some studies, tissue oxygen tension has been measured in septic patients and found not to be low.

DCA, in the presence of oxygen, stimulates pyruvate dehydrogenase activity and increases oxidation of pyruvate to acetyl coenzyme A and carbon dioxide, thereby increasing pyruvate and lactate metabolism. DCA reduces blood lactate in septic patients. Some have argued, therefore, that deficits in cellular oxygen cannot be the rate limiting step in lactate accumulation, ${ }^{36}$ but instead there is increased pyruvate production or decreased lactate clearance. $^{9}$ Lactate reductions in septic patients treated with DCA are modest, however. In one study, with of a pretreatment mean value of $11.6 \mathrm{mmol} / \mathrm{l}$, the reduction was between 1 and $3 \mathrm{mmol} / 1$, and one third of patients had less than a $20 \%$ decrease in blood lactate concentration. ${ }^{13}$ There was still an excess of lactate that was not eliminated by this DCA induced aerobic process, which might be attributable to cell hypoxia.

The absence of an apparent delivery dependent relation between $\mathrm{DO}_{2}, \mathrm{VO}_{2}$, and lactate does not exclude dysoxia as the cause of high lactate in sepsis. Supply dependent oxygen 
consumption at a tissue level might be poorly detected by the global values of $\mathrm{VO}_{2}$ and $\mathrm{DO}_{2}$, even if independent and valid methods are used to measure each variable. It is untested whether regional measures of dysoxia, such as the hepatic venous $\beta$-hydroxybutyrate to acetoacetate ratio, ${ }^{40}$ would better determine whether supply dependent oxygen consumption exists in sepsis, and how sensitive high blood lactate is at reflecting this.

If tissue hypoxia is not the major cause of lactate accumulation in sepsis, then what other mechanisms are involved? Levraut et al showed that haemodynamically stable adults with sepsis and mildly raised blood lactate had more than a $50 \%$ reduced lactate clearance compared with septic adults who had normal lactate, whereas lactate production was similar in the two groups. ${ }^{9}$ Reduced activation of the pyruvate dehydrogenase complex in sepsis ${ }^{41}$ might cause the accumulation of pyruvate and formation of lactate.

Although mitochondrial $\mathrm{PO}_{2}$ might be normal in sepsis, theoretically, ATP production would be reduced by impaired delivery of pyruvate into the Krebs cycle, inhibition of mitochondrial enzymes in the Krebs cycle or electron transport chain, or other disruption of mitochondrial function. ${ }^{42}$ What has been termed "cytopathic hypoxia" might really be a cytopathic inability to use available oxygen. This is well defined-for example, in cyanide poisoning, where cytochromes are inhibited and aerobic metabolism ceases. Whether a similar mechanism operates in clinical sepsis, what causes it, and whether it contributes to hyperlactataemia are uncertain.

\section{Lactate and prediction of outcome in critically ill children}

Whatever the causes of hyperlactataemia, high or rising blood lactate might help identify children at high risk of mortality.

SEPSIS

We prospectively compared the predictive value of several variables for mortality and major sequelae in 31 children admitted to the intensive care unit (ICU) with severe sepsis. Those variables were: mean arterial pressure, heart rate, arterial $\mathrm{pH}$, base deficit, gastric intramucosal $\mathrm{pH}$, and blood lactate. ${ }^{43}$ These were measured at the time of admission and 12, 24, and 48 hours later. There were 10 deaths and 21 survivors. Blood lactate was the earliest predictor of mortality, and identified survivors from those who subsequently died, when measured as early as 12 hours after admission. Twelve hours after admission a blood lactate $>3 \mathrm{mmol} / 1$ had a positive predictive value for death of $56 \%$, and a lactate of $3 \mathrm{mmol} / 1$ or less had a positive predictive value for survival of $84 \%$. At 24 hours, a lactate $>3 \mathrm{mmol} / \mathrm{l}$ had a positive predictive value for death of $71 \%$, and a lactate of $3 \mathrm{mmol} / 1$ or less had a positive predictive value for survival of $86 \%$. No other variable identified deaths from survivors as early as 12 hours.
CARDIAC SURGERY

Siegel and colleagues ${ }^{18}$ measured arterial blood lactate in 41 children after cardiopulmonary bypass. The mean (SD) lactate concentration for survivors was significantly lower than for the seven who died $(2.38(0.13) \mathrm{mmol} / 1 v 6.86$ (0.79) $\mathrm{mmol} / \mathrm{l})$. Higher lactate concentrations on admission to the ICU were significantly associated with an increased number of extracardiac organ systems failing in the postoperative period, and were positively correlated with total bypass and circulatory arrest times.

We compared the predictive power of markers of cardiovascular function for clinically important major postoperative adverse events in a prospective cohort study of 90 children after cardiopulmonary bypass. ${ }^{19}$ Heart rate, blood pressure, cardiac output by thermodilution, oxygen delivery, base deficit, mixed venous oxygen saturation, blood lactate, gastric intramucosal $\mathrm{pH}$, and toe core temperature gradient were measured at the time of admission to the ICU, and every four hours thereafter. We also recorded the duration of cardiopulmonary bypass, aortic cross clamping, and circulatory arrest. The major postoperative adverse events of interest were cardiac arrest, need for emergency chest opening, need for commencement of extracorporeal life support, development of multiple organ failure, and death. The subjects were selected for their high risk for major postoperative adverse events, and included 23 neonates having the arterial switch procedure, and 23 infants undergoing repair of multiple ventricular septal defects. In the series, 12 children had major postoperative adverse events and three died. The variables that were the earliest predictors of major postoperative adverse events were the duration of cardiopulmonary bypass, the blood lactate at the time of admission to the ICU, and admission hypotension. Blood lactate was the most consistent predictor of major postoperative adverse events, identifying subsequent major postoperative adverse events when measured also at four and eight hours after admission. Gastric intramucosal $\mathrm{pH}$ was also predictive of major postoperative adverse events, but was a later predictor than lactate. At no time in the first 24 hours after ICU admission were cardiac output, oxygen delivery, mixed venous oxygen saturation, or the toe core temperature gradient predictive of major postoperative adverse events. Lactate might be a useful indicator of children at risk of major morbidity and mortality after cardiac surgery. Of note, a high lactate did not predict more than one third of all major postoperative adverse events so, although a specific marker of risk of such events, it had poor sensitivity.

\section{NEONATAL INTENSIVE CARE}

Hyperlactataemia has been described as an early marker of sepsis $^{44}$ and necrotising enterocolititis $^{45}$ in preterm neonates. Deshpande et al measured lactate, arterial $\mathrm{pH}$, and base excess in 75 mechanically ventilated newborns, most of whom were premature. ${ }^{29}$ They found significantly higher blood lactate in those who died compared with survivors. After a 
neonate developed hyperlactataemia (defined as a blood lactate $>2.5 \mathrm{mmol} / \mathrm{l}$ ), a substantial fall in lactate was more likely to occur in survivors. There might be an element of survivor bias in this finding. The time frame that this reduction occurred in is not specified and if the second lactate concentration was recorded at a variable time interval from the first, this might have allowed the lactate of those who survived to fall. This study could demonstrate no predictable relation between lactate concentrations, arterial $\mathrm{pH}$, or base excess. Lactate was a better predictor of outcome than the other acid-base variables.

EXTRACORPOREAL LIFE SUPPORT

Cheung and Finer ${ }^{46}$ described 28 neonates requiring extracorporeal membrane oxygenation, in whom lactate concentrations were higher on admission among non-survivors than survivors. Twelve hours after the start of extracorporeal membrane oxygenation, lactate concentrations had fallen significantly in survivors, but not in those who died. These authors also demonstrated absence of a close relation between lactate and other acid-base variables. In an underpowered study we found lactate was not useful in discriminating survivors from deaths on extracorporeal life support but that $\mathrm{DCO}_{2}$ (measured by gastric tonometry) was. ${ }^{47}$

\section{Management of lactic acidosis}

A monitoring variable with predictive power becomes truly valuable to the clinician at the bedside if treatment can be adjusted, based on the variable, and adverse events avoided or outcome improved. To my knowledge, there is only one controlled trial with adequate power that has tested an intervention based on blood lactate and measured important clinical outcomes. ${ }^{13}$ Several other trials, using empirical interventions to increase $\mathrm{DO}_{2}$, allow limited conclusions to be made about the management of hyperlactataemia in circulatory failure.

\section{DICHLOROACETATE}

Stacpoole et al tested whether specific treatment of the lactic acidosis of circulatory shock with DCA could reduce mortality. ${ }^{13}$ There was a significant, but clinically small, reduction in lactate concentrations and an increase in arterial $\mathrm{pH}$ in the treatment group; however, there were no improvements either in haemodynamics or survival. Only $12 \%$ of the DCA treated group survived to hospital discharge, compared with $17 \%$ of the group who received placebo.

BICARBONATE

The treatment of lactic acidosis with bicarbonate is based on the notion that: (1) the cardiovascular or metabolic effects of acidosis or hyperlactataemia are harmful per se; and (2) there are net cardiovascular or metabolic benefits when bicarbonate is given.

Does metabolic acidosis depress myocardial performance and responses to catecholmines? Although there is evidence to support this, ${ }^{48}{ }^{49}$ bicarbonate might worsen intracellular acidosis by generated $\mathrm{CO}_{2}$, which enters the cytoplasm, ${ }^{50}$ and might further depress myo- cardial function..$^{45} 52$ However, the evidence that bicarbonate administration causes paradoxical intracellular acidosis is contentious. In cell preparations, the effect on intracellular $\mathrm{pH}$ of adding bicarbonate to extracellular fluid depends on the starting $\mathrm{pH}$ of the system, the size of the bicarbonate boluses added to the system, and the type of buffering solutions used as the extracellular suspension. In vitro studies that have reproduced metabolic acidosis, ${ }^{53} 54$ which used physiological solutions buffering the extracellular fluid, ${ }^{53}$ and added bicarbonate as a series of small boluses, ${ }^{54}$ have shown only small and transient reductions in intracellular $\mathrm{pH}$.

What of the effect of bicarbonate on myocardial function? Two canine studies found transient increases in coronary venous $\mathrm{CO}_{2}$ and decreases in myocardial contractility at the beginning of an infusion of sodium bicarbonate. $^{5255}$ This was followed by improved contractile function beyond baseline levels. One study documented a reduction in intracellular $\mathrm{pH}^{52}$ whereas the other study showed no change in intracellular $\mathrm{pH}$, but a decrease in serum free $\mathrm{Ca}^{2+}$, coinciding with myocardial depression. ${ }^{55}$ These investigators proposed that myocardial depression after bicarbonate infusion might be caused by reduced availability of free $\mathrm{Ca}^{2+}$, rather than intracellular acidosis. ${ }^{55}$

The effect of bicarbonate on the intracellular $\mathrm{pH}$ in other organs is similarly contentious. In a rabbit model of hypoxic lactic acidosis, brain intracellular acidosis was partially corrected by bicarbonate administration ${ }^{56}$; however, in a study of five normal adult humans, intravenous sodium bicarbonate resulted in a reduction in brain intracellular $\mathrm{pH}$, measured by magnetic resonance imaging spectroscopy. ${ }^{57}$ Despite all this, it is not known whether the therapeutic correction of intracellular acidosis is without adverse effects, and one experimental study shows that intracellular acidosis might protect against reperfusion injury.

It has been proposed that the effect of bicarbonate in shifting the haemoglobin-oxygen dissociation curve to the left will result in delayed tissue reoxygenation. In a porcine model of haemorrhagic shock, bicarbonate delayed increases in tissue $\mathrm{PO}_{2}$, and delayed falls in plasma lactate. ${ }^{58}$ This study used small patient numbers, and repeated measures over time, but analysed differences in the data at time intervals that were not predetermined. Therefore, the conclusions are not strongly supported.

Clinical trials of bicarbonate in children are few. Fanconi et $a l,^{59}$ in an open nonrandomised, "before and after" trial in neonates with metabolic acidosis, examined the cardiovascular effects of bicarbonate infusion. Sodium bicarbonate induced a transient increase in cardiac output and a fall in systemic vascular resistance. Although this appears at odds with the animal models described above, ${ }^{525}$ from this clinical study there is no way of telling whether the effect was because of bicarbonate correction of acidosis, or because 


\section{Table 1 Protocol to manage high blood lactate in sepsis *}

Give intravenous fluid volume bolus of $10-20 \mathrm{ml} / \mathrm{kg}$ of colloid or normal saline

Continuously monitor

- arterial blood pressure

- central venous pressure (CVP)

- heart rate

cutaneous oxygen saturation $\left(\mathrm{SpO}_{2}\right)$

- urine output

Maintain CVP at $8-12 \mathrm{~mm} \mathrm{Hg}$ with fluid volume

Up to $40-60 \mathrm{ml} / \mathrm{kg}$ might be required in the first six hours

Optimise $\mathrm{SpO}_{2}$ with oxygen and mechanical ventilation

Transfuse with packed cells if haemoglobin $<100 \mathrm{~g} / 1$

Give clotting products as volume if there is a coagulopathy, but beware of hypotension caused by fresh frozen plasma

Repeat lactate; if still high or blood pressure low, add dopamine at $5 \mu \mathrm{g} / \mathrm{kg} / \mathrm{min}$

Apply mechanical ventilation to reduce respiratory muscle oxygen consumption and allow redistribution of cardiac output to vital organs

Increase inotropic support if lactate still rising

Consider that catecholamines, especially adrenaline (epinephrine), might also cause high lactate concentrations

If the child is receiving adrenaline, and has an acceptable blood pressure but a rising lactate, reducing the adrenaline infusion rate might lower lactate

Titrate the inotrope to the lowest infusion rate that will maintain

- a blood pressure in the normal range for age

- a urine output $>1 \mathrm{ml} / \mathrm{kg} / \mathrm{hour}$

- a reduction in lactate

If lactate continues to rise despite these measures, consider the use of extracorporeal life support

^Assumes appropriate antibiotics have been given.

Table 2 Protocol to manage high blood lactate after cardiopulmonary bypass

Correct deficits in oxygen delivery

- maintain adequate circulating volume

- maintain haemoglobin at $120-140 \mathrm{~g} / 1$

do not stop dopamine on first postoperative nigh

- optimise arterial oxygen saturation

Give paracetamol for fever and use other cooling methods as necessary (to normothermia)

Do not stop neuromuscular blocking drugs or wean off ventilation on first postoperative night

unless there is a specific reason (for example, Fontan, Glenn), and then only with frequent reassessment of perfusion

Start peritoneal dialysis early if the child has generalised oedema, oliguria, or large volumes of fluid are required to maintain circulation

Repeat lactate at four and eight hours after intensive care unit (ICU) admission

If lactate is rising, or $>4 \mathrm{mmol} / 1$

- notify the ICU consultant and cardiac surgeon

- check cardiac rhythm and perform echocardiography to examine cardiac function and exclude pericardial effusion

optimise intravascular volume

Consider the following

- increasing dopamine to $7.5-10 \mu \mathrm{g} / \mathrm{kg} / \mathrm{min}$

- adding another inotrope if mean arterial pressure is low

- the possible detrimental effects of high dose catecholamine constrictors

- the need for vasodilators

- cardiac tamponade (as a result of mediastinal oedema or haemorrhage)

Frequent assessment of the child is required

ICU admission lactate $>5 \mathrm{mmol} / \mathrm{l}$ has a $30 \%$ risk of major adverse events. Lactate at four hours $>4 \mathrm{mmol} / \mathrm{l}$ has a $45 \%$ risk of major adverse events.

of fluid volume, or infusion of a hyperosmolar solution.

Therefore, the theoretical disadvantages of administered bicarbonate are: (1) complications of hyperosmolar solutions, particularly an increased risk of intraventricular haemorrhages in neonates; (2) ventilatory failure and arterial hypercarbia in patients with compromised pulmonary function; (3) worsening of intracellular acidosis; and (4) delayed tissue reoxygenation.

The current role of bicarbonate that is supported by an arguable balance of evidence is as small titrated doses to achieve a $\mathrm{pH}$ compatible with optimal cardiovascular responsiveness, while attempts to improve oxygenation are continued. ${ }^{51}$

\section{GENERAL MEASURES TO IMPROVE OXYGEN}

DELIVERY

Several randomised, controlled trials in adults have tested whether the empirical driving of $\mathrm{DO}_{2}$ to levels seen in survivors of critical illness will have a survival benefit for all patients. Results are conflicting, reflecting the heterogeneity of patients enrolled, differences in interventions used, and the timing of interventions. In a meta-analysis of these studies it was concluded that interventions designed to achieve supraphysiological goals of oxygen transport variables did not reduce mortality. ${ }^{37}$ There are dangers of massive dose inotropic support, such as was used in some of these trials. High dose catecholamines can cause tachyarrhythmia, myocardial ischaemia, ${ }^{60}$ and worsen lactic acidosis. ${ }^{61}$

What therefore is a rational approach to the problem of hyperlactataemia if it is not solely caused by impaired tissue oxygenation, and if no specific treatment has been proved to be beneficial? Tables 1 and 2 suggest guidelines for the management of high lactate in children with sepsis and after cardiac surgery. For many patients with hyperlactataemia, management that includes fluid volume expansion will produce a fall in lactate and a favourable clinical response. ${ }^{15}$ Large volumes of fluid might need to be given early in the treatment of children with septic shock. ${ }^{62}$ Titrating inotropic drugs to the lowest infusion dose that will achieve an acceptable blood pressure, a urine output of $>1 \mathrm{ml} / \mathrm{kg} /$ hour, improve peripheral perfusion, and correct acidosis might be as precise as can be currently achieved.

In children with severe circulatory failure, mechanical ventilation can result in a redistribution of $15-20 \%$ of the cardiac output away from the muscles of respiration to other vital organs.

Effective management requires non-specific treatment based on considerations of the following: the underlying pathology; the child's fluid volume status, cardiovascular, and respiratory function; liver function and drugs; and the effects of dysoxia on the brain, gastrointestinal tract, and kidneys.

A normal blood lactate in children with severe circulatory failure might also have clinical relevance; it should prompt consideration of associated conditions that might impair lactate production, such as depletion of glucose stores in malnutrition. It remains untested whether there is any metabolic abnormality common to children with fatal septic shock who never have hyperlactataemia.

\section{Future directions in the monitoring of dysoxia}

The earliest detection of dysoxia might be found by specific measures of the redox state of cells. The $\beta$-hydroxybutyrate to acetoacetate (ketone body) ratio estimates liver mitochondrial NADH/NAD, and has been shown to be a marker of oxygen limited ATP flux in liver, ${ }^{40}$ and a predictor of adverse events after liver transplantation. What role it may have in other pathologies is unclear. Near infrared spectroscopy might be useful to monitor cytochrome redox states. ${ }^{63}$ The lactate to pyruvate ratio, reflecting the redox potential of the cytosol, might be a more specific marker of dysoxia than lactate alone. Before any new technique is adopted for practice, careful clinical studies in critically ill children, which compare the 
predictive value for major adverse events, and the cost effectiveness, with those of established techniques, will be needed.

\section{Conclusions}

In dysoxia, oxygen limited ATP production produces lactic acid, but this is not the only mechanism for excess lactate in critically ill patients. There is not a direct relation between lactate concentrations and supply dependent oxygen consumption in all patients, although current techniques to test this are imprecise. One of the causes of mild hyperlactataemia in sepsis is impaired lactate removal. The role of lactate in the management of critically ill children is in alerting clinicians to a higher risk of mortality or adverse events, and it is but one useful tool to monitor response to treatment. The immediate management depends on consideration of the aetiology of hyperlactataemia. High blood lactate does not suggest a universal therapeutic response, but indicates severe physiological derangement associated with an increased risk of mortality. Lactate concentrations are not well predicted by other acid-base variables, and lactate is a better predictor of adverse outcomes, including mortality. Hyperlactataemia might be a specific predictor of morbidity risk, but in a population of critically ill children, has low sensitivity.

In children with hyperlactataemia it is sensible to consider whether there are correctable deficits in oxygen delivery. Current treatment aimed at lowering the lactate concentration by specifically altering a biochemical pathway does not improve survival, and neither does driving $\mathrm{DO}_{2}$ to supranormal levels with inotropes. Bicarbonate infusion has a limited role, and is only effective in normalising blood $\mathrm{pH}$ when generated $\mathrm{CO}_{2}$ is eliminated from the body. In many cases there will be identifiable and avoidable causes of insufficient tissue oxygen delivery, such as hypovolaemia or inadequate cardiac output.

Further research is required to define more sensitive, and equally inexpensive and noninvasive, markers of tissue dysoxia.

1 Balaban RS. Regulation of oxidative phosphorylation in the mammalian cell. Am f Physiol 1990;258:C377-89.

2 Gutierrez G. Cellular energy metabolism during hypoxia. Crit Care Med 1991;19:619-26.

3 Nunn JF. Oxygen. In: Nunn JF, ed. Nunn's applied respiratory physiology. Oxford: Butterworth-Heinmann Ltd, 1993: 247-305.

4 Connett RJ, Honig CR, Gayeski EJ, Brooks GA. Defining hypoxia: a systems view of $\mathrm{VO}_{2}$, glycolysis, energetics, and hypoxia: a systems view of $\mathrm{VO}_{2}$, glycolysis, energ
intracellular $\mathrm{PO}_{2}$. F Appl Physiol 1990;68:833-42.

intracellular $\mathrm{PO}_{2}$. F Appl Physiol 1990;68:833-42.
5 Rosenkrantz TS, Kubin J, Mishra OP, Smith D, DelivoriaRosenkrantz TS, Kubin J, Mishra OP, Smith D, Delivoria-
Papadopoulos M. Brain cell membrane $\mathrm{Na}^{+}, \mathrm{K}^{+}$-ATPase activity following severe hypoxic injury to the newborn pigactivity following severe hypo

6 West MA, Wilson C. Hypoxic alterations in cellular signal transduction in shock and sepsis. New Horiz 1996;4:168 78.

7 Carroll JM, Toral-Barza L, Gibson G. Cytosolic free calcium and gene expression during chemical hypoxia. $\mathcal{F}$ Neurochem 1992;59:1836-43.

8 Harper IS, Bond JM, Chacon E, Reece JM, Herman B, Lemasters JJ. Inhibition of $\mathrm{Na}+\mathrm{H}+$ exchange preserves viability, retores mechanical function, and prevents the $\mathrm{pH}$ paradox in reperfusion injury to rat neonatal myocytes. Basic Res Cardiol 1993;88:430-42.

9 Levraut J, Ciebiera J-P, Chave S, et al. Mild hyperlactatemia in stable septic patients is due to impaired lactate clearance rather than overproduction. Am Rev Respir Dis 1998;157: rather than $1021-6$.

10 Druml W, Grimm G, Laggner AN, Lenz K, Scheenweib B. Lactic acid kinetics in respiratory alkalosis. Crit Care Med 1991;19:1120-4
11 Stacpoole PW, Wright EC, Baumgartner TG, et al. Natural history and course of acquired lactic acidosis in adults. DCA-lactic acidosis study group. Am f Med 1994;97:47-54. 12 Mizock BA, Falk JL. Lactic acidosis in critical illness. Crit Care Med 1992;20:80-93.

13 Stacpoole PW, Wright EC, Baumgartner TG, et al. A controlled clinical trial of dichloroacetate for treatment of lactic acidosis in adults. $N$ Engl F Med 1992;327:1564-9.

14 Silverman HJ. Lack of relation between induced changes in oxygen consumptio

15 Vincent J-L, Dufaye P, Berre J, Leeman M, Deguate JP, Jahn RJ. Serial lactate determinations during circulatory shock. Crit Care Med 1983;11:449-51.

16 Ruiz CE, Weil MH, Carlson RW. Treatment with circulatory shock with dopamine. Studies on survival. $\mathcal{F} A M A 1979$; 242:165-8.

17 Ariza M, Gothard JWW, Macnaughton P, Hooper J, Morgan CJ, Evans TW. Blood lactate and mixed venous-arterial $\mathrm{PCO} 2$ gradient as indices of poor peripheral perfusion following cardiopulmonary bypass. Intensive Care Med 1991; 17:320-4.

18 Siegel LB, Hauser GJ, Hertzog JH, Hopkins RA, Hannan $\mathrm{RL}$, Dalton HJ. Initial post-operative serum lactate predicts outcome in children after open heart surgery [abstract]. Crit Care Med 1995;23:A205.

19 Duke TD, Butt W, South M, Karl TR. Markers of major adverse events in children after cardiac surgery. F Thorac Cardiovasc Surg 1997;114:1042-52.

20 Shangraw RE, Winter R, Hromco J, Robinson ST, Gallaher EJ. Amelioration of lactic acidosis with dichloroacetate during liver transplantation in humans. Anesthesiology 1994;81:1127-38.

21 Duff JH, Groves MD, McLean APH. Defective oxygen consumption in septic shock. Surg Gynecol Obstet 1969;5: 1051-60.

22 Waxman K, Nolan LD, Shoemaker WC. Sequential peri-operative lactate determination. Crit Care Med 1982;

23 Dantzker DR. Physiological and biochemical indicators of impaired tissue oxygenation. In: Reinhart K, Eyrich K, eds. Clinical aspects of oxygen transport and tissue oxygenation. Berlin: Springer-Verlag, 1989:182-94

24 Cady LD, Weil MH, Afifi AA. Quantitation of severity of critical illness with special reference to blood lactate. Crit Care Med 1973;1:75-80.

25 Broder G, Weil MH. Excess lactate: an index of reversibility of shock in human patients. Science 1964;143:1467-59.

26 Anderson CT, Westgard JO, Schlimgen K, Birnbaum ML. Contribution of arterial blood lactate measurements to the
care of critically ill patients. Am f Clin Pathol 1977;68:63-7.

27 Cowan BN, Burns HJG, Boyle P, Ledingham IM. The relative prognotic value of lactate and hemodynamic measurements in early shock. Anaesthesia 1984;39:750-5.

28 Abou-Khalil B, Scalea TM, Trooskin SZ, Henry SM, Hitchcock R. Hemodynamic responses to shock in young trauma patients: need for invasive monitoring. Crit Care Med 1994;22:633-9.

29 Deshpande SA, Platt MPW. Association between blood lactate and acid-base status and mortality in ventilated babies. Arch Dis Child 1997;76:F15-20.

30 Tuchschmidt J, Fried J, Swinney R, Sharma OP. Early hemodynamic correlates of survival in septic shock. Crit Care Med 1989;17:719-23.

31 Cohen RD, Woods HF. Clinical and biochemical aspects of lactic acidosis. Boston: Blackwell Scientific Publications, 1976.

32 Flaegstad T, Kaaresen PI, Gutteberg T. Factors associated with fatal outcome in childhood meningococcal diease. with fatal outcome in childhood meni
Acta Physiol Scand 1995;84:1137-42.

33 Mercier J-C, Beaufils F, Hartman J-F, Azema D. Hemodynamic patterns of meningococcal shock in children. Crit Care Med 1988;16:27-33.

34 Uusaro A. Gastric tonometry, tissue hypoxia and MSOF. Is there a link? Intensive Care Med 1998;24:753-5.

35 Gilbert EM, Haupt MT, Mandanas RY, Huaringa AJ, Carlson RW. The effect of fluid loading, blood transfusion, and catecholamine infusion on oxygen delivery and consumption in patients with sepsis. Am Rev Respir Dis 1986;134: 873-8.

36 Gore D, Jahoor F, Hibbert J. Lactic acidosis during sepsis is related to increased pyruvate production; not deficits in tissue oxygen availability [abstract]. Crit Care Med 1996;24: A100.

37 Heyland DK, Cook DJ, King D, Kernerman P, BrunBuisson C. Maximising oxygen delivery in critically ill patients: a methodologic appraisal of the evidence. Crit Care Med 1996;24:517-24.

38 Ronco JJ, Fenwick JC, Wiggs BR, Phang PT, Russel JA, Tweedale MG. Oxygen consumption is independent of increases in oxygen delivery by dobutamine in septic patients who have normal or increased plasma lactate. $\mathrm{Am}$ Rev Respir Dis 1993;147:25-31.

39 Eichacker PQ, Hoffman WD, Danner RL. Serial measurements of total body oxygen consumption in an awake canine model of septic shock. Am $\mathcal{F}$ Respir Crit Care Med 1996;154:68-75.

40 Dishart MK, Schlichtig R, Tonnessen TI, et al. Mitochondrial redox as a potential detector of liver dysoxia in-vivo. $\mathcal{f}$ Appl Physiol 1998;84:791-7.

41 Vary TC, Siegel JH, Nakatani T, Sato T, Aoyama H. Effects of sepsis on activity of pyruvate dehydrogenase complex in skeletal muscle and liver. Am ₹ Physiol 1986;250:E634-40.

42 Fink M. Cytopathic hypoxia in sepsis. Acta Anaesthesiol Scand 1997;110:S87-5. 
43 Duke TD, Butt W, South M. Predictors of mortality and multiple organ failure in children with sepsis. Intensive Care Med 1997;23:684-92

44 Fitzgerald MJ, Gota M, Myers TF, Zeller WP. Early metabolic effects of sepsis in the preterm infant: lactic acidosis and increased glucose requirement. If Pediat 1992;121:951-5.

45 Ryan CA, Fischer J, Gayle M, Wenman W. Surgical and postoperative management of two neonates with necrotizing fasciitis. Can $\mathcal{F}$ Surg 1993;36:337-41.

46 Cheung P-Y, Finer N. Plasma lactate concentration as a predictor of death in neonates with severe hypoxemia requiring extracorporeal membrane oxygenation. F Pediat 1994;125:763-8.

47 Duke T, Butt W, South M, Shann F, the RCH ECMO Nursing Team. The $\mathrm{DCO}_{2}$ measured by gastric tonometry predicts survival in children receiving extracorporeal life support. Chest 1997;111:174-9.

48 Ng ML, Levy MN, Zieske HA. Effects of changes of $\mathrm{pH}$ and of carbon dioxide tension on left ventricular performance. Am ₹ Physiol 1967;213:115-20.

49 Shapiro JI. Pathogenesis of cardiac dysfunction during metabolic acidosis: therapeutic implications. Kidney Int metabolic acidosis:

50 Rhee KH, Toro LO, McDonald GG, Nunnally RL, Levin DL. Carbicarb, sodium bicarbonate, and sodium chloride in hypoxic lactic acidosis. Effect on arterial blood gases, lactate concentrations, hemodynamic variables, and myocardial intracellular pH. Chest 1993;104:913-18.

51 Biebuyck JF. Sodium bicarbonate in the treatment of subtypes of acute lactic acidosis: physiologic considerations. Anesthesiology 1990;72:1064-76.

52 Sonett J, Pagani FD, Baker LS, et al. Correction of intramyocardial hypercarbic acidosis with sodium bicarbonate. Circ Shock 1994;42:163-73.

53 Levraut J, Labib Y, Chave S, Payan P, Raucoules-Aime M, Grimaud D. Effect of sodium bicarbonate on intracellular $\mathrm{pH}$ under different buffering conditions. Kidney Int pH under differer
54 Goldsmith DJ, Forni LG, Hilton PJ. Bicarbonate therapy and intracellular acidosis. Clin Sci (Colch) 1999;93:593-8.

55 Rao RS, Graver ML, Urivetsky M, Scharf SM. Mechanisms of myocardial depression after bolus injection of sodium bicarbonate. F Crit Care 1994;9:255-61.

56 Sessler D, Mills P, Gregary G, Litt L, James T. Effects of bicarbonate on arterial and brain intracellular $\mathrm{pH}$ in neonatal rabbits recovering from hypoxic lactic acidosis. 7 Pediatr 1987;111:817-23.

57 Nakashima K, Yamashita T, Kashiwagi S, Nakayama N, Kitahara T, Ito $\mathrm{H}$. The effect of sodium bicarbonate on $\mathrm{CBF}$ and intracellular $\mathrm{pH}$ in man: stable Xe-CT and 31PMRS. Acta Neurol Scand 1996;166:96-8.

58 Makisalo HJ, Soini HO, Nordin AJ, Hockerstedt KAV. Effects of bicarbonate therapy on tissue oxygenation during resuscitation of hemorrhagic shock. Crit Care Med 1989;17:1170-4.

59 Fanconi S, Burger R, Ghelfi D, Uehlinger J, Arbenz U. Hemodynamic effects of sodium bicarbonate in critically ill neonates. Intensive Care Med 1993;19:65-9.

60 Timmins AC, Hayes M, Yau E, Watson JD, Hinds CJ. The relationship between cardiac reserve and survival in critically ill patients receiving treatment aimed at achieving upranormal oxygen delivery and consumption. Postgrad Med f 1992;68:S34-40.

61 Day NPJ, Phu NH, Bethell DP, et al. The effects of dopamine and adrenaline on acid-base balance and systemic haemodynamics in severe infection. Lancet 1996; 348:219-23.

62 Carcillo JA, Davis AL, Zaritsky A. Role of early fluid resuscitation in pediatric septic shock. FAMA 1991;266:12425.

63 Rhee P, Langdale L, Mock C, Gentilello LM. Near-infrared spectroscopy: a continuous measurement of cytochrome oxidation during hemorrhagic shock. Crit Care Med 1997;25:166-70. 